OPEN ACCESS

Edited by:

Wilhelm Heinrich Holzapfel,

Handong Global University,

South Korea

Reviewed by:

Maria Guadalupe Vizoso Pinto, National Scientific and Technical

Research Council, Argentina

Marcela Carina Audisio,

Instituto de Investigaciones para la Industria Química (INIQUI)-CONICET,

Argentina

*Correspondence:

Clemencia Chaves-Lopez

cchaveslopez@unite.it

Annalisa Serio

aserio@unite.it

Specialty section:

This article was submitted to

Food Microbiology,

a section of the journa

Frontiers in Microbiology

Received: 29 April 2016

Accepted: 14 July 2016

Published: 29 July 2016

Citation:

Chaves-Lopez C, Serio A,

Delgado-Ospina J, Rossi C, Grande-Tovar CD and Paparella A

(2016) Exploring the Bacterial Microbiota of Colombian Fermented Maize Dough "Masa Agria" (Maiz Añejo). Front. Microbiol. 7:1168. doi: 10.3389/fmicb.2016.01168

\section{Exploring the Bacterial Microbiota of Colombian Fermented Maize Dough "Masa Agria" (Maiz Añejo)}

\author{
Clemencia Chaves-Lopez ${ }^{1 *}$, Annalisa Serio ${ }^{1 *}$, Johannes Delgado-Ospina ${ }^{2}$, \\ Chiara Rossi ${ }^{1}$, Carlos D. Grande-Tovar ${ }^{2}$ and Antonello Paparella ${ }^{1}$
}

${ }^{1}$ Faculty of Bioscience and Technology for Food, Agriculture and Environment, University of Teramo, Mosciano Sant'Angelo, Italy, ${ }^{2}$ Grupo de Biotecnología, University of San Buenaventura Sede Cali, Cali, Colombia

Masa Agria is a naturally fermented maize dough produced in Colombia, very common in the traditional gastronomy. In this study we used culture-dependent and RNA-based pyrosequencing to investigate the bacterial community structure of Masa Agria samples produced in the south west of Colombia. The mean value of cell density was 7.6 log CFU/g of presumptive lactic acid bacteria, $5.4 \mathrm{log} \mathrm{cfu} / \mathrm{g}$ for presumptive acetic bacteria and $5.6 \mathrm{og} \mathrm{CFU} / \mathrm{g}$ for yeasts. The abundance of these microorganisms is also responsible for the low $\mathrm{pH}(3.1-3.7)$ registered. Although the 16S rRNA pyrosequencing revealed that the analyzed samples were different in bacteria richness and diversity, the genera Lactobacillus, Weissella, and Acetobacter were predominant. In particular, the most common species were Lactobacillus plantarum and Acetobacter fabarum, followed by L. fermentum, L. vaccinostercus, and Pediococcus argentinicus. Several microorganisms of environmental origin, such as Dechloromonas and most of all Sphingobium spp., revealed in each sample, were detected, and also bacteria related to maize, such as Phytoplasma. In conclusion, our results elucidated for the first time the structures of the bacterial communities of Masa Agria samples obtained from different producers, identifying the specific dominant species and revealing a complete picture of the bacterial consortium in this specific niche. The selective pressure of tropical environments may favor microbial biodiversity characterized by a useful technological potential.

Keywords: fermented maize, pyrosequencing, Lactobacillus, Acetobacter, dough

\section{INTRODUCTION}

Maize or corn (Zea mays), the "gift of the goddess" of the ancient Amerindians, is a cereal crop that is produced in a wide range of agro-ecological environments worldwide. Archeological evidence from the central Andes indicates that the role of maize changed between A.D. 500 and 1500, shifting from a culinary item, simply prepared by boiling, to a more complex symbolic food with elaborated political meanings, transformed by grinding and chewing into beer (Hastorf and Johannessen, 1993). Today maize plays an extremely important role in the Andean culture and is the main cereal grain in Colombia, as measured by production of $260.700 \mathrm{Ha}^{1}$ (2015).

${ }^{1}$ www.dane.gov.co 
Fermented foods, besides being more than a pleasure and a satisfaction of nutritional needs, are a rich source of insight into many aspects of cultural life (Hastorf and Johannessen, 1993). Since pre-Hispanic times, fermented products from maize have been consumed widely in Colombia (Chaves-López et al., 2014a), where their manufacturing remains a traditional art in houses, villages, and small-scale industries. In Colombian fermented foods and beverages, microbial interactions have been demonstrated to be of paramount importance in the development of the particular traits of the final product (Chaves-López et al., 2014b).

Masa Agria, also known as Maiz añejo, is a traditional fermented maize dough, produced in Colombia, which is still prepared by natural fermentation. In the traditional method of preparation, described by Chaves-López et al. (2014a), yellow maize kernels are peeled, covered with water, and stored in a hot place $\left(35\right.$ to $\left.40^{\circ} \mathrm{C}\right)$ to favor spontaneous fermentation. The period of fermentation varies from 3 to 5 days and determines the degree of sourness with a final $\mathrm{pH}$ from 4.4 to 3.8. After fermentation, the grains are washed with water, drained and milled, and then a dough is formed and allowed to stand for 3 or 5 days. During this period, dehydration occurs, and $a_{\mathrm{w}}$ is reduced at different levels depending on the producers. As reported by the same authors, fermentation is triggered mainly by lactic acid bacteria (LAB) and yeasts that are able to reach values of about 8.8 and $6.8 \log \mathrm{CFU} / \mathrm{g}$, respectively. Masa Agria is a very common product in Colombian gastronomy, as it is commonly used to prepare soups, tamales (dough filled with meat and vegetables and cooked in a banana leaf), empanadas (cooked dough filled with meat and potatoes and then fried), carantanta (the leftover material in the bottom of the pot that is peeled off after cooked Masa Agria for empanadas) and envueltos (dough steamed in a corn husk).

In the last years, metagenomic analyses have been broadly used to investigate microbial communities of fermented foods (Sakamoto et al., 2011; Chao et al., 2013; Elizaquível et al., 2015; Minervini et al., 2015). In general, these studies revealed a widely unknown microbial biodiversity, underreported by conventional cultivation-based methods. Although several studies have been conducted to explore the bacterial comunities in fermented maize doughs from different countries, to the best of our knowledge no information is available on the microbial communities of the Colombian Masa Agria. Therefore, the aim of this study is to explore the microbial diversity of Colombian Masa Agria by pyrosequencing of $16 \mathrm{~S}$ rRNA of the bacterial microbiota, to improve the knowledge on microbial communities that can be essential for product characterisation and process optimization (Oguntoyinbo et al., 2011).

\section{MATERIALS AND METHODS}

\section{Masa Agria Samples}

Six distinct samples of Masa Agria from different producers of Valle del Cauca (Colombia) were acquired. Producers were located in the north (producer 1), north-east (2 and 6), and south $(3,4$ and 5$)$ of the region. Samples were immediately refrigerated and transferred to the laboratory for the following analyses.

\section{Microbiological Analyses}

Ten grams of each sample were mixed with $90 \mathrm{~mL}$ of $0.85 \%$ (w/v) sterile physiological saline, and homogenized in a Stomacher Labblender 400 Circulator (Seward, Worthing, UK) for $2 \mathrm{~min}$. Serial dilutions were prepared in the same diluent. Total viable count was determined on Plate Count Agar, after incubation at $30^{\circ} \mathrm{C}$ for $48 \mathrm{~h}$. Sabouraud Dextrose Agar added with Chloramphenicol (Sigma-Aldrich), incubated at $25^{\circ} \mathrm{C}$ for $72 \mathrm{~h}$, was used for the enumeration of yeasts, while fungi were detected on Czapek Dox Agar after 5 days of incubation at $25^{\circ} \mathrm{C}$.

Presumptive LAB were enumerated on Man, Rogosa and Sharpe (MRS) agar and presumptive enterococci on Slanetz and Bartley, both incubated anaerobically by means of anaerobic jars and BBL GasPak anaerobic system envelopes (Becton Dickinson, Cockeysville, MD, USA) at $37^{\circ} \mathrm{C}$ for $48 \mathrm{~h}$. Micrococci and staphylococci were determined on Mannitol Salt Agar, incubated at $35^{\circ} \mathrm{C}$ for $48 \mathrm{~h}$. Presumptive Pseudomonas spp. were counted on Pseudomonas Agar Base added with CFC supplement after $48 \mathrm{~h}$ at $25^{\circ} \mathrm{C}$. Total coliforms were detected on Violet Red Bile Agar (VRBA) incubated at $37^{\circ} \mathrm{C}$ for $24 \mathrm{~h}$. Finally acetic bacteria were enumerated on GYC Agar (Conda, Pronadisa, Madrid, Spain) supplemented with $3.0 \mathrm{~g} / \mathrm{L} \mathrm{CaCO}_{3}$ (SigmaAldrich, Milan, Italy).

All media were from Oxoid-Thermofisher (Rodano, Italy), except where differently specified. Three repetitions for each sample were performed.

\section{Physical-Chemical Analyses}

The $\mathrm{pH}$ value was determined using a $\mathrm{pH}$ meter (Mettler Toledo MP 220, Novate Milanese, Italy). Aliquots of $10 \mathrm{~g}$ of Masa Agria were homogenized thoroughly with $10 \mathrm{~mL}$ of distilled water and the homogenate was used for $\mathrm{pH}$ determination.

The water activity $\left(a_{\mathrm{w}}\right)$ of the samples was determined by means of Aqualab instrument model Series 3 (Decagon Devices, Pullman, WA, US).

Three replicates were analyzed for each sample.

\section{RNA Extraction from Masa Agria Samples and Pyrosequencing Analysis}

An aliquot of about $200 \mathrm{mg}$ of each Masa Agria sample was diluted in RNAlater (Sigma-Aldrich) and was then used for RNA extraction by Stool total RNA purification kit (Norgen Biotech Corporation, Thorold, ON, Canada). Total RNA was treated with RNase-free DNase I (Roche, Almere, Netherlands; $10 \mathrm{U}$ of DNase for $20 \mu \mathrm{g}$ of RNA) for $20 \mathrm{~min}$ at room temperature. Quality and concentration of RNA extracts were determined by using 1\% agarose-0.5X Tris borate EDTA (TBE) gels and by spectrophotometric measurements performed at 260, 280, and $230 \mathrm{~nm}$ by using the NanoDrop ${ }^{\circledR}$ ND-1000 Spectrophotometer (Thermo Scientific- Wilmington, DE, USA). Random examers and the Tetro cDNA synthesis kit (Bioline, Taunton, US) were used to transcribe the extracted RNA (about $2.5 \mu \mathrm{g}$ ) to cDNA, according to the manufacturer's instructions (Gowen and Fong, 2010).

For each dough, three cDNA samples were used for bacterial tag-encoded FLX amplicon pyrosequencing (bTEFAP), which 
was performed by Research and Testing Laboratories (RTL, Lubbock, TX, USA), using a 454 FLX Sequencer (454 Life Sciences, Branford, CT, USA). The bTEFAP procedures were performed on the basis of RTL protocols http://www.research andtesting.com (Research and Testing Laboratories, Lubbock, TX, USA). cDNA was analyzed by bTEFAP, using primers forward 28F:GAGTTTGATCNTGGCTCAG and reverse 519R: GTNTTACNGCGGCKGCTG based upon the V1-V3 region of the 16S rRNA gene (Escherichia coli position 27-519; Suchodolski et al., 2012). Following sequencing, the QIIME pipeline version ${ }^{2}$ 1.4.0, with default settings, was used to screen, trim, and filter raw sequence data. $\mathrm{B} 2 \mathrm{C}^{3}$ ) was used to exclude chimeras, according to Gontcharova et al. (2010). Sequences lower than 250 bp were removed. FASTA sequences for each sample, without chimeras, were evaluated.

\section{Bioinformatics and Data Analysis}

The sequences were first clustered into OTUs (operational taxonomic units) clusters with $97 \%$ identity (3\% divergence) using USEARCH sequence analysis tool ${ }^{4}$. To determine the microbial identities, sequences were first queried using a distributed BLASTn algorithm (Dowd et al., 2005) against a database of high-quality $16 \mathrm{~S}$ bacterial sequences derived from NCBI. Database sequences were characterized as high quality based on the similar criteria originally described by Ribosomal Database Project (RDP, v10.28; Cole et al., 2009).

Operational taxonomic units were identified using the appropriate taxonomic levels using a database of high quality sequences derived from NCBI.

First, overall richness (i.e., number of distinct organisms present within the microbiome; alpha diversity) was expressed as the number of OTUs, and was quantified using the Chaol richness estimator:

$$
\mathrm{S}_{\text {chaol }}=\mathrm{S}_{\mathrm{obs}}+\frac{\mathrm{n} 1(\mathrm{n} 1-1)}{2(\mathrm{n} 2+1)}
$$

where $n_{\mathrm{i}}$ is the number of OTU with abundance $i$.

Second, overall diversity (which is determined by both richness and evenness, the distribution of abundance among distinct taxa) was expressed as Shannon Diversity. Shannon diversity $\left(H^{\prime}\right)$ is calculated using:

$$
H^{\prime}=-\sum_{i=1}^{R} p i \ln (\mathrm{pi})
$$

where $R$ is richness and $p i$ is the relative abundance of the $i$ th OTU.

Venn diagrams were realized on the bases of the OTUs obtained for the different species, according to Heberle et al. (2015).

\section{Statistical Analysis}

All values are shown as means with the standard deviation. The data on microbial population were analyzed by ANOVA.

${ }^{2}$ http://qiime.sourceforge.net

${ }^{3} \mathrm{http} / / / \mathrm{www} \cdot$ researchandtesting.com/B2C2.html

${ }^{4} \mathrm{http}: / /$ drive5.com/usearch
Differences among means were studied using the Tukey's test at a $p$-value of $<0.05$, using statistical software STATISTICA 7.0 (Statsoft, Tulsa, OK, USA) for Windows.

As regards pyrosequencing results, the relative abundance of each OTU was determined for each sample and the differences between the samples were calculated using Student's $t$-test.

Principal Component Analysis was performed to analyze dissimilarities among the samples regarding their bacterial species, using statistical software STATISTICA 7.0 (Statsoft, Tulsa, OK, USA) for Windows.

\section{RESULTS}

\section{Physical-Chemical Parameters}

Table 1 shows the values of $\mathrm{pH}$ and water activity measured in the Masa Agria samples. The analyses revealed some differences among samples from different producers. In particular, samples from producer 3 showed the lowest $a_{\mathrm{w}}$ values, with significant $(p<0.05)$ differences with respect to the other samples (except for sample 6), probably suggesting a more advanced age, thus implying a higher dehydration. In general, $\mathrm{pH}$ values of the analyzed Masa Agria samples were lower of equal than 3.76, as a consequence of the metabolic activity of LAB and acetic bacteria. Samples obtained by producer 5 were characterized by the lowest $\mathrm{pH}$ values, around 3.12 .

\section{Microbiological Profile of Masa Agria Samples}

Microbial counts (Table 2) revealed a mesophilic aerobic population comprised between 7.4 and $7.9 \mathrm{log} \mathrm{CFU} / \mathrm{g}$, with samples 1 and 4 showing the highest counts.

Plate counts confirmed that the viable microbiota was dominated by the association of presumptive LAB and yeasts, as already observed by Chaves-López et al. (2014b), together with acetic bacteria, particularly in samples from producers 3 , 4, and 5. Counts comprised between 2.0 and $2.9 \mathrm{log} \mathrm{CFU} / \mathrm{g}$ were observed for presumptive enterococci. The presence of micro-staphylococci was instead variable: while counts of 3.4 and 3.8 were observed in samples 3 and 5, respectively, they were undetectable $(<2.0 \log \mathrm{CFU} / \mathrm{g})$ in samples 2,4 , and 6 .

Significantly different numbers $(p<0.05)$ were counted for presumptive Pseudomonas spp. in the different samples, with

TABLE 1 | Physical-chemical parameters of Masa Agria samples obtained from six different producers.

\begin{tabular}{lcc}
\hline Producer & $\mathbf{p H}$ & $\mathbf{a}_{\mathbf{w}}$ \\
\hline 1 & $3.76 \pm 0.01$ & $0.994 \pm 0.001$ \\
2 & $3.56 \pm 0.02$ & $0.992 \pm 0.002$ \\
3 & $3.56 \pm 0.01$ & $0.989 \pm 0.002$ \\
4 & $3.63 \pm 0.02$ & $0.997 \pm 0.001$ \\
5 & $3.12 \pm 0.02$ & $0.997 \pm 0.001$ \\
6 & $3.58 \pm 0.03$ & $0.991 \pm 0.002$ \\
\hline
\end{tabular}

Data are expressed as mean of three repetitions \pm standard deviation. 
TABLE 2 | Microbial counts detected in Masa Agria samples obtained from 6 different producers.

\begin{tabular}{|c|c|c|c|c|c|c|}
\hline Microbial group & Producer 1 & Producer 2 & Producer 3 & Producer 4 & Producer 5 & Producer 6 \\
\hline Mesophilic aerobic count & $7.87 \pm 0.00$ & $7.43 \pm 0.05$ & $7.54 \pm 0.03$ & $7.90 \pm 0.02$ & $7.38 \pm 0.02$ & $7.63 \pm 0.04$ \\
\hline Lactic acid bacteria & $8.15 \pm 0.03$ & $7.93 \pm 0.02$ & $7.56 \pm 0.04$ & $7.95 \pm 0.02$ & $7.91 \pm 0.03$ & $7.93 \pm 0.01$ \\
\hline Enterococci & $2.60 \pm 0.02$ & $2.50 \pm 0.01$ & $2.76 \pm 0.02$ & $2.88 \pm 0.02$ & $2.04 \pm 0.03$ & $2.01 \pm 0.02$ \\
\hline Staphylococci & $2.03 \pm 0.01$ & $<2.00$ & $3.40 \pm 0.03$ & $<2.00$ & $3.82 \pm 0.03$ & $<2.00$ \\
\hline Acetic bacteria & $2.48 \pm 0.03$ & $3.50 \pm 0.04$ & $7.40 \pm 0.04$ & $7.80 \pm 0.03$ & $7.80 \pm 0.05$ & $3.72 \pm 0.02$ \\
\hline Pseudomonas & $<2.00$ & $<2.00$ & $2.46 \pm 0.01$ & $3.42 \pm 0.02$ & $3.75 \pm 0.03$ & $2.23 \pm 0.03$ \\
\hline Coliforms & $<1.00$ & $2.48 \pm 0.01$ & $<1.00$ & $<1.00$ & $<1.00$ & $2.30 \pm 0.04$ \\
\hline Yeasts & $5.60 \pm 0.04$ & $6.60 \pm 0.05$ & $5.16 \pm 0.03$ & $5.47 \pm 0.02$ & $5.13 \pm 0.03$ & $5.78 \pm 0.03$ \\
\hline Molds & $2.36 \pm 0.02$ & $2.50 \pm 0.01$ & $2.76 \pm 0.03$ & $2.88 \pm 0.04$ & $2.04 \pm 0.02$ & $2.43 \pm 0.01$ \\
\hline
\end{tabular}

Data are expressed as Log CFU/g (mean of three repetitions \pm Standard Deviation).

TABLE 3 | Comparison of estimates OTUs, richness and diversity indices of the 16S rRNA gene libraries as obtained from the pyrosequencing analysis.

\begin{tabular}{lcccc}
\hline & $\begin{array}{c}\text { Number of } \\
\text { Reads }\end{array}$ & $\begin{array}{c}\text { Number of } \\
\text { OTUs }\end{array}$ & Chao 1 & Shannon \\
\hline Producer 1 & 34076 & 15 & 15 & 1.48 \\
Producer 2 & 34001 & 28 & 25 & 2.27 \\
Producer 3 & 33947 & 18 & 9 & 1.45 \\
Producer 4 & 34006 & 18 & 8 & 1.23 \\
Producer 5 & 34105 & 15 & 9 & 1.38 \\
Producer 6 & 33862 & 33 & 25 & 2.21 \\
\hline
\end{tabular}

counts below $2.0 \log \mathrm{CFU} / g$ only in samples 1 and 2. Coliforms were detected only in samples 2 and 6.

\section{Sequencing Statistics and Diversity Estimate}

Pyrosequencing of the bacterial 16S rRNA genes generated more of 33.800 reads for each samples. The optimized data at $97 \%$ sequence similarity cut-off are shown in Table 3 . The bacterial community was analyzed by richness estimator (Chao 1), and diversity index (Shannon). In general samples from producers 2 and 6 harbored higher bacterial diversity (Shannon index) than the other samples and similar patterns of richness (Chao 1), as shown in Table 3.

\section{Microbial Community Structure}

Taxonomy-based analysis showed a total of seven bacteria Phyla (Bacterioidetes, Actinobacteria, Cyanobacteria, Firmicutes, Proteobacteria, Planctomycetes, and Tenericutes).

Firmicutes was the major Phylum in the different fermented doughs, containing for more than $47 \%$ of all the bacterial community (Figure 1). The relative abundance of Proteobacteria, detected in each sample, was lower than Firmicutes, in particular in the samples from producers 1, 2, and 3, while Phylum Tenericutes was found only in samples of producers 1, 2, and 6 . Bacteriodetes and Planctomycetes were present only in samples from producers 3 and 6 , respectively.

In Table 4 the relative abundance of microbial components at Family level in Masa Agria doughs is reported. Firmicutes were divided in three families (Lactobacillaceae, Leuconostocaceae, and Streptococcaceae), with Lactobacillaceae as the most abundant, accounting for a minimum of $28.5 \%$ (producer 3 ) to $89 \%$ (producer 1), followed by the sequences attributed to Leuconostocaceae, up to $18.2 \%$ (producer 2), and $20.1 \%$ (producer 6). Streptococcaceae were present only in samples from producers $2(3.7 \%), 4(0.04 \%)$, and $6(6.2 \%)$.

Proteobacteria Phylum was represented by nine families: Acetobacteriaceae, Sphingomonadaceae, Rhodocyclaceae, Comamonadaceae, Enterobacteriaceae, Moraxellaceae, Xanthomonadaceae, Thiotrichaceae, and Pseudomonadaceae. In particular Acetobacteriaceae family was present in all the samples and was the most abundant family, accounting for $100 \%$ of Proteobacteria in sample from producer 4. Except for samples 4 and 1, in which only two families where represented (Acetobacteraceae and Sphingomonadaceae), OTUs of at least five families were present.

Planctomycetes Phylum, that was only a smaller proportion of the samples profile, was represented only by Planctomycetaceae family, with a incidence of $0.09 \%$ in sample from producer 3 . Tenericutes Phylum was represented by the Acholeplasmataceae family that accounted for 9.91, 40.35, and $23.5 \%$ in samples from producers 1,2 , and 6 , respectively.

At genus level, the number of identified OTUs of the samples varied depending on the producer: the samples from producers 2 and 6 were characterized by the major presence of OTUs, with 14 and 21 different genera, respectively, while in the other samples $6,11,6$, and 8 OTUs were revealed (in samples from producers $1,3,4$, and 5, respectively), as described in Table 5. The top 9 most abundant OTU demonstrated that Lactobacillus, belonging to Firmicutes Phylum (ranging from 17.3 to $89.3 \%$ ), dominated in all the samples followed by Acetobacter (Proteobacteria phylum; from 0.36 to $69.9 \%$ ) and Weissella (from 0.03 to $19.1 \%$ ) (Table 5).

Pediococcus was present in all samples with the exception of sample from producer 5 . Several sub-dominants genera (less than $4 \%$ ), belonging to Proteobacteria (Comamonas, Enterobacter, Escherichia, Serratia, and Acinetobacter), were identified only in samples from producers 2 and 6. Sphingobium was detected in all samples excepted for sample 5. Dechloromonas, and Thiothrix were found in the samples from producers 3 and 5, while Pseudomonas was also found in samples from producer 6 . Gemmata was found only in sample 5. 


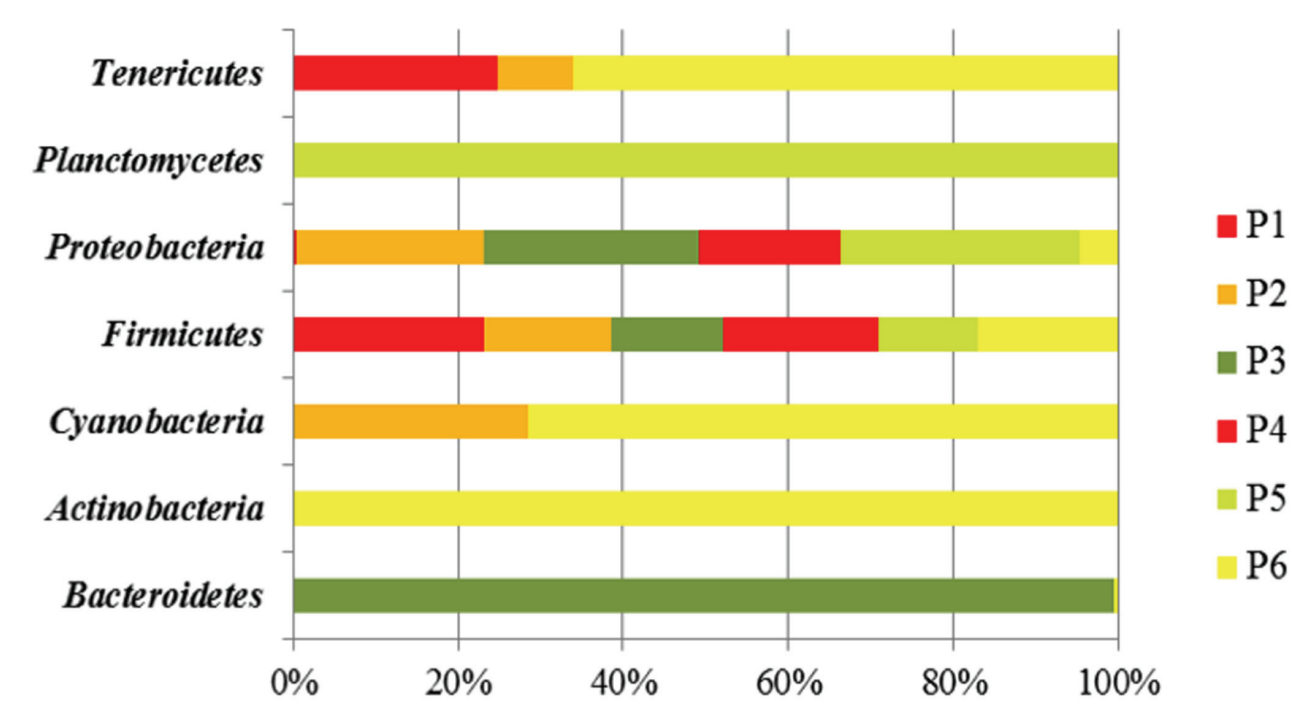

Relative abundance

FIGURE 1 | Bacterial community diversity in six Masa agria samples from different producers (P, producers). The relative abundance of bacterial $16 \mathrm{~S}$ rRNA genes was estimated through classification at the Phyla level.

TABLE 4 | Bacterial community diversity in six samples of Masa Agria from different producers ( $P$, producer).

\begin{tabular}{|c|c|c|c|c|c|c|}
\hline Family & P1 & P2 & P3 & P4 & P5 & P6 \\
\hline Flavobacteriaceae & - & - & 0.20 & - & - & 0.03 \\
\hline Streptomycetaceae & - & - & - & - & - & 2.15 \\
\hline Bacteroidaceae & - & - & 0.09 & - & - & - \\
\hline Lactobacillaceae & 89.38 & 29.64 & 28.52 & 29.69 & 33.04 & 39.14 \\
\hline Leuconostocaceae & 0.10 & 18.17 & 0.45 & 0.27 & 0.03 & 20.11 \\
\hline Streptococcaceae & & 3.70 & - & 0.04 & - & 6.27 \\
\hline Acetobacteraceae & 0.36 & 4.50 & 69.94 & 69.49 & 65.54 & 5.82 \\
\hline Sphingomonadaceae & 0.20 & 0.50 & 0.22 & - & 0.41 & 1.0 \\
\hline Rhodocyclaceae & - & - & 0.02 & - & 0.03 & - \\
\hline Comamonadaceae & - & 0.08 & - & - & - & 0.17 \\
\hline Moraxellaceae & - & 0.08 & - & - & - & 0.07 \\
\hline Enterobacteriaceae & - & 0.26 & - & - & - & 0.41 \\
\hline Pseudomonadaceae & - & - & 0.07 & - & 0.47 & 0.06 \\
\hline Thiotricaceae & - & - & 0.33 & - & 0.31 & - \\
\hline Xanthomonadaceae & - & 0.043 & - & - & - & 0.07 \\
\hline Planctomycetaceae & - & - & - & - & 0.09 & - \\
\hline Acholeplasmataceae & 9.91 & 40.35 & - & - & - & 23.49 \\
\hline Unknown & - & 0.04 & - & - & - & 0.06 \\
\hline Unclassified & - & - & - & - & - & 0.1 \\
\hline
\end{tabular}

The relative abundance of bacterial 16S rRNA genes was estimated through classification at the Family level.

The analysis on the species level showed that a certain percentage of the readers could not be classified to any existant group, which is common in pyrosequencing, because many uncultured bacteria can be detected or because they represent new species. The total number of OTUs at species level was 56, of which $15,27,18,18,15$, and 33 were detected in the samples from producers 1 to 6 .
Venn diagrams were plotted in order to evidence similarities among different microbial communities in the different samples, in terms of OTUs overlapping (Figure 2). As evidenced, only 2 OTUs were shared by all maize dough samples. The number of shared OTUs among the dough producers was low; for example, 11 between doughs from producer 1 and producer 2, while 8 between doughs from producer 2 and producer 3 . Doughs from 
TABLE 5 | Bacterial community diversity in Masa Agria.

\begin{tabular}{|c|c|c|c|c|c|c|}
\hline Genus & P1 & P2 & P3 & P4 & P5 & P6 \\
\hline Bacteroides & - & - & 0.08 & - & - & - \\
\hline Streptomyces & - & - & - & - & - & 0.07 \\
\hline Chryseobacterium & - & - & 0.20 & - & - & 0.03 \\
\hline Planktothricoides & - & - & - & - & - & 0.10 \\
\hline Lactobacillus & 89.33 & 26.86 & 17.35 & 26.80 & 33.03 & 37.30 \\
\hline Pediococcus & 0.051 & 2.78 & 11.17 & 2.87 & - & 3.83 \\
\hline Leuconostoc & - & 0.91 & 0.22 & - & - & 0.97 \\
\hline Weissella & 0.10 & 17.28 & 0.22 & 0.27 & 0.03 & 19.13 \\
\hline Lactococcus & - & 3.78 & - & 0.03 & - & 6.20 \\
\hline Streptococcus & - & - & - & - & - & 0.06 \\
\hline Gemmata & - & - & - & - & 0.09 & - \\
\hline Acetobacter & 0.36 & 4.57 & 69.93 & 69.33 & 65.54 & 6.92 \\
\hline Sphingomonas & - & - & - & - & - & 0.03 \\
\hline Comamonas & - & 0.08 & - & - & - & 0.03 \\
\hline Enterobacter & - & 0.17 & - & - & - & 0.12 \\
\hline Delftia & - & - & - & - & - & 0.14 \\
\hline Escherichia & - & 0.04 & - & - & - & 0.27 \\
\hline Serratia & - & 0.04 & - & - & - & 0.03 \\
\hline Acinetobacter & - & 0.08 & - & - & - & 0.06 \\
\hline Frateuria & - & 0.04 & - & - & - & - \\
\hline Gluconobacter & - & - & - & 0.015 & - & - \\
\hline Sphingobium & 0.23 & 0.52 & 0.223 & - & 0.41 & 1.01 \\
\hline Dechloromonas & - & - & 0.22 & - & 0.03 & - \\
\hline Pseudomonas & - & - & 0.06 & - & 0.47 & 0.06 \\
\hline Thiothrix & - & - & 0.33 & - & 0.03 & - \\
\hline Stenotrophomonas & - & - & - & - & - & 0.07 \\
\hline Candidatus Phytoplasma & 9.91 & 40.35 & - & - & - & 23.49 \\
\hline
\end{tabular}

The relative abundance of bacterial 16S rRNA genes was estimated through classification at the genera level.

producers 2 and 6 shared the greatest number of OTUs, with 24 common species. Number and abundance of OTUs from rRNA samples are reported in Supplementary Table S1, with taxonomic details up to species level when such assignment was possible.

To analyze bacterial community at species level among the different producers, a heat-map plot was generated using the relative abundance of the OTUs (Figure 3). As evidenced, the dominant OTUs in doughs from producers 1, 2, and 6 were different from those of the producers 3,4 , and 5 . In fact in dough from producer 1, L. gallinarum (62\%) was dominant, Sugarcane phytoplasma (40\%) in dough from producer 2, and L. fermentum in dough 6 (19\%), while doughs from producers 3, 4, and 5 were dominated by species of the genus Acetobacter, such as Acetobacter cibinongensis, A. fabarum, A. lovaniensis, and $A$. orientalis. It has to be underlined that the producers 1,2 , and 6 are located in the north/north-east of the region, while the others were located in the south, thus suggesting differences in the environmental conditions (i.e., temperature, water, and maize provenance).

Lactobacillus plantarum and A. fabarum were the most common species in all the samples, independently on the producers.

In further analyses, aimed at highlighting the microbiota similarity among the different producers, a PCA on the realtive abundance of bacterial species was performed (Figure 4). The PC1 accounted for the $67.67 \%$ of the variance while PC2 for $18.48 \%$. Samples were separated in three cluster: cluster I containing sample from producer 1, was distinguished by the relative high percentages in OTUs of $L$. pontis, $L$. panis, L. gallinarum, L. coleohominis, and Lactobacillus spp. Cluster II was formed by samples from producers 3, 4, and 5 , that were characterized by a relative high abundance of L. plantarum and Acetobacter spp. The samples from producers 2 and 6 were included in cluster III, featuring a high relative abundance of OTUs of Lactobacillus species, Weissella fabaria and S. phytoplasma, and contained also unique species, probably due to different geographical origin of maize and producers.

\section{DISCUSSION}

In this preliminar study, we used the pyrosequencing of tagged $16 \mathrm{~S}$ rRNA gene amplicons to explore the bacterial microbiota in Colombian maize fermented dough Masa Agria. The data here presented provide a detailed insight of the bacterial profile of this product, as in our knowledge this is the first report of the bacterial community and structure of this Colombian fermented dough. 


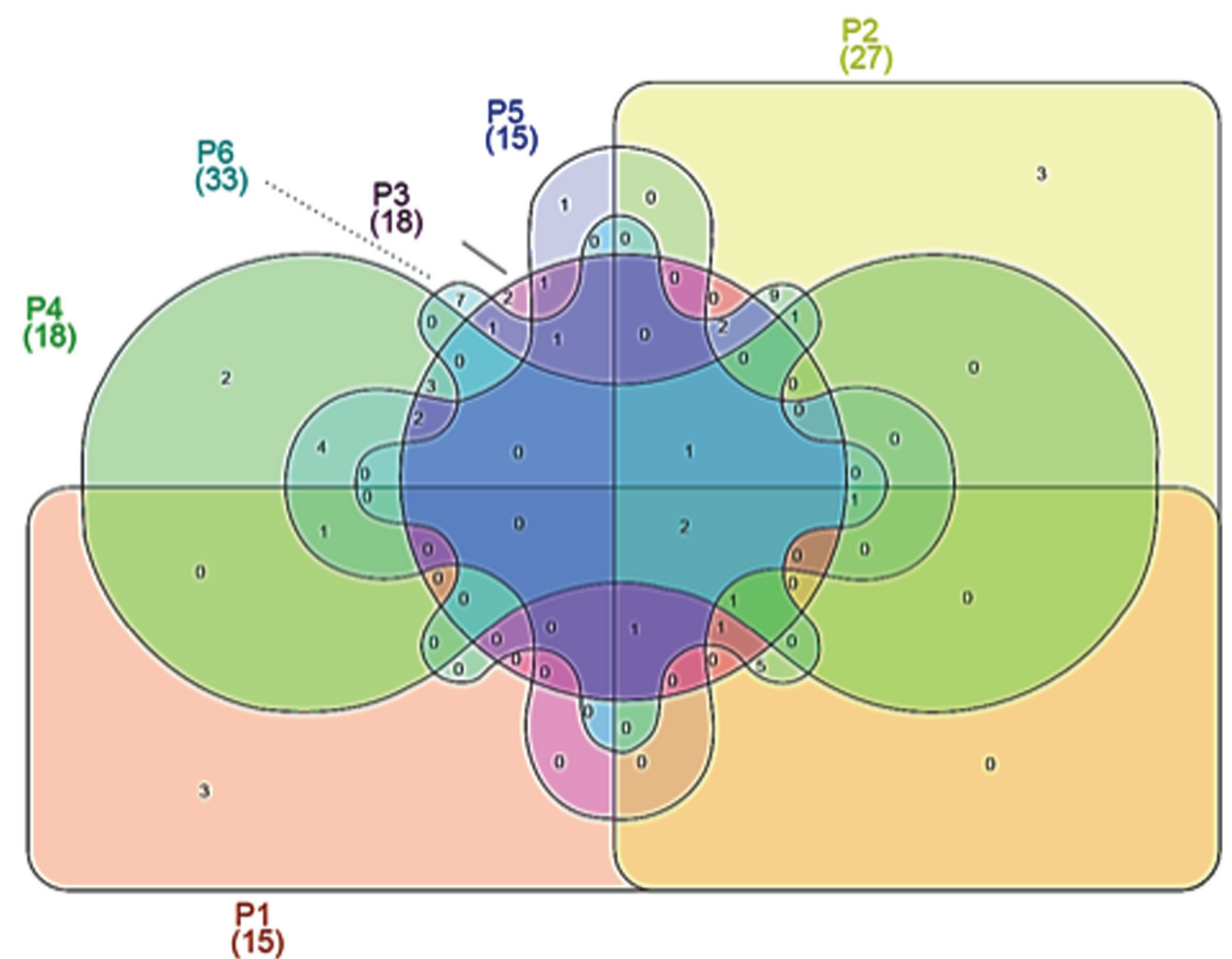

FIGURE 2 | Venn diagrams showing operational taxonomic units (OTUs) at species level, depicting similarities and differences among in the microbial community in six Masa agria samples from different producers ( $P$, producers).

Microbial culture revealed growth on the plate counts media used. While the presence of presumptive Lactococcus, Lactobacillus, acetic bacteria and Pseudomonas was confirmed by $16 S$ rRNA pyrosequencing, micro-staphylococci and enterococci were not confirmed. Enterococci may derive from raw materials, such as maize kernels or water, from the environment, and also from the tools used during grain milling and dough manufacturing (Elizaquível et al., 2015). Being able to grow over a wide range of temperature and easily supporting acid pH (Giraffa, 2002; Serio et al., 2010), their presence in the fermented Masa Agria would be unsurprising. Nevertheless our Masa Agria samples were market samples, analyzed at the end of the fermentations process, therefore enterococci deriving from raw materials and environment could have been overgrown by LAB species, as it happens in sourdough, where they are usually found in the first days (De Vuyst et al., 2014). Some authors reported that Slanetz and Bartley Agar lacks of selectivity when used for food samples, as it could over-estimate the actual number of enterococci, being able to support the growth also of lactococci and some Lactobacillus strains (Klein and Reuter, 2012). On the other side, also Mannitol Salt Agar was demonstrated to give false positive results as regards staphylococci, therefore lacking of specificity (Kircher et al., 2002). Pseudomonas spp. were present at extremely low sequence reads; indicating that the counts of bacteria that grew on the medium used (PSB + CFC) were unlikely to be all Pseudomonas. In fact, although the used medium is selective for this genus, the growth of other Gramnegative bacteria such as Serratia marcescens, Aeromonas spp., Xanthomonas spp., Alcaligenes spp., and Acinetobacter spp. is possible (Krueger and Sheikh, 1987).

The presence of lactobacilli, acetic bacteria and yeasts explains the low $\mathrm{pH}$ values profiles of the analized doughs from six different producers. The $\mathrm{pH}$ values observed in Masa Agria samples, are compatible with those reported in literature for other maize doughs (Annan et al., 2003). Chaves-López et al. (2014b) reported the presence of lactic and acetic acids in Masa Agria samples obtained from the same geographic area in Colombia. These acids not only are responsible for the sour taste, but their effect in $\mathrm{pH}$ reduction play a key role in the activation of endogenous and bacterial phytases, increasing dough nutritional value. In fact, phytic acid complexes amino acids and minerals, therefore acting as anti-nutritional factor. High $\mathrm{LAB}$ abundance and low $\mathrm{pH}$ are also responsible for coliforms decrease (Elizaquível et al., 2015).

Our findings showed that complex microbiota is associated to natural fermented maize doughs and that community membership and structure considerably differed depending on the producer. In fact, some OTUs were detected only in samples from one producer; in addition, the bacterial composition changed in terms either of species and of their relative abundance. This is not surprising, because the bacterial composition of fermented doughs differed on the bases of ecological parameters 

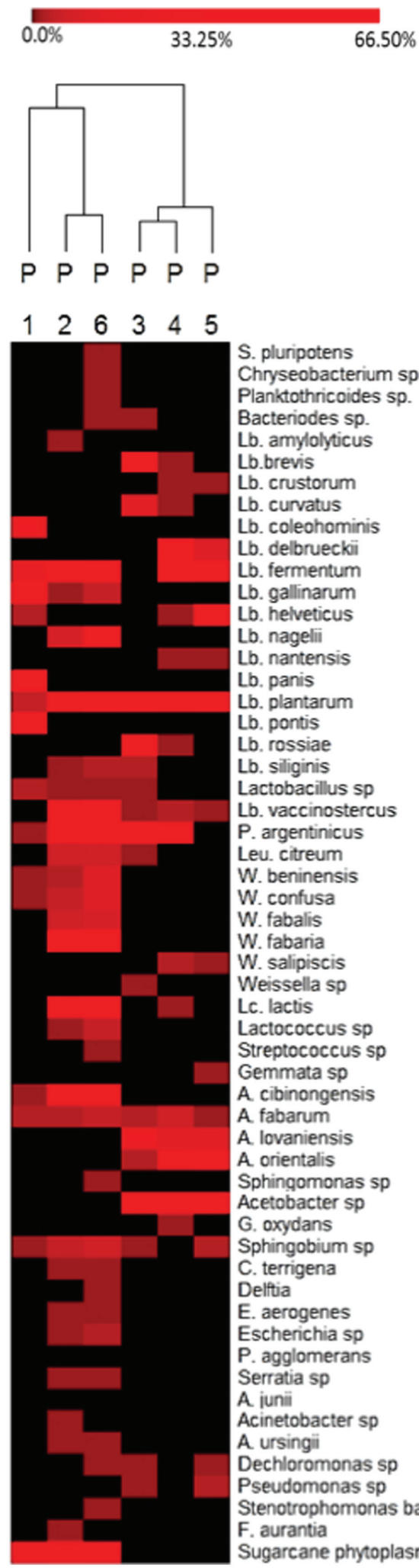

S. pluripotens

Chryseobacterium sp

Planktothricoides sp.

Bacteriodes sp.

Lb. amylolyticus

Lb.brevis

Lb. crustorum

Lb. curvatus

Lb. coleohominis

Lb. delbruecki

Lb. fermentum

Lb. gallinarum

Lb. helveticus

Lb. nagelii

Lb. nantensis

Lb. panis

Lb. plantarum

Lb. pontis

Lb. rossiae

Lb. siliginis

Lactobacillus sp

Lb. vaccinostercus

$P$. argentinicus

Leu. citreum

$W$. beninensis

W. confusa

W. fabalis

W. fabaria

W. salipiscis

Weissella $s p$

Lc. lactis

Lactococcus sp

Streptococcus sp

Gemmata sp

A. cibinongensis

A. fabarum

A. lovaniensis

A. orientalis

Sphingomonas sp

Acetobacter $\mathrm{sp}$

G. oxydans

Sphingobium sp

C. terrigena

Delftia

E. aerogenes

Escherichia sp

P. agglomerans

Serratia sp

A junii

Acinetobacter sp

A. ursingii

Dechloromonas sp

Pseudomonas sp

Stenotrophomonas bacterium

F. aurantia

Sugarcane phytoplasma

FIGURE 3 | Heat-map depicting bacterial diversity and relative abundance of species in six Masa agria samples from different producers ( $P$, producers), as revealed by $16 S$ rRNA pyrosequencing. The color key defines the percentages of OTUs in the samples. such as type of maize used, temperature, time of fermentation, water activity, etc. Another possible explanation for differences among the samples could derive from phytochemical treatments that the maize was subjected to, during the cultivation. In fact, the total microbial population and the relative species proportion on maize grains can be affected by many factors, mainly temperature and rainfall, physical damage due to insects and application of phytopharmaceuticals. Although the producers of the analyzed samples of Masa Agria in this study did not know the provenience of the maize, in Colombia it is cultivated from 350 to 2400 meters above sea level. Thus it is evident that bacteria from this natural environment are different and their growth during the fermentation process lead to particular treats of each Masa Agria.

Interestingly, $4 \%$ of the readings could not be associated with a known species suggesing that Masa Agria may be an unexplored reservoir of unknown bacterial species.

In different Masa Agria many bacterial species have been found, and some of them have been commonly reported in indigenous Mexican or African fermented maize dough, considerably contributing to the development of the final characteristics of the products (Ben-Omar and Ampe, 2000; Escalante et al., 2001; Abriouel et al., 2006; Assohoun-Djenia et al., 2016). However, the predominant bacterial consortium depends on its source of production with mixtures of maltose and non-maltose fermenting species. As regards the bacterial active population in Masa Agria, evidenced by $16 \mathrm{~S}$ rRNA pyrosequencing, it is immediately clear that LAB, and particularly Lactobacillus spp. and Weissella spp., together with Acetobacter spp., were dominant in all the samples. In particular, while several differences were observed among samples from the different producers, the two species L. plantarum and A. fabarum were common in all the analyzed doughs. The sequences obtained in the samples from the different producers exhibited high similarities and the species $L$. fermentum, L. vaccinostercus, $P$. argentinicus, and Sphingobium spp. were repeatedly found. This observation suggests that these particular species could play a specific role in Masa Agria production and that they could be a typical microbiota of this type of maize fermented product, although the variability should be deeply investigated.

In Mexican fermented maize dough Pozol, Escalante et al. (2001) reported the dominance of Lc. lactis followed by L. alimentarius, L. plantarum, and Streptococcus suis. In addition, Ben-Omar and Ampe (2000), studying the bacterial succession during its production, at the end of the fermentation detected L. plantarum, L. fermentum, L. casei, S. bovis, Bifidobacterium minimum, or Exiguobacterium aurantiacum. Halm et al. (1993) concluded that a homogenous group of obligatively heterofermentative lactobacilli related to L. fermentum and L. reuteri played a dominating role during the production of Ghanaian maize dough Kenkey. On the other hand, the analysis of bacterial community composition of maize dough samples from the Congo Republic, by $16 \mathrm{~S}$ rRNA gene temporal temperature gradient gel electrophoresis (TTGE), revealed that the most intense band corresponded to L. plantarum/paraplantarum; moreover, although other bacteria such as L. gasseri, Enterococcus spp., L. delbrueckii, L. reuteri, L. casei, L. acidophilus, L. delbrueckii, E. coli, and Bacillus spp. 
A

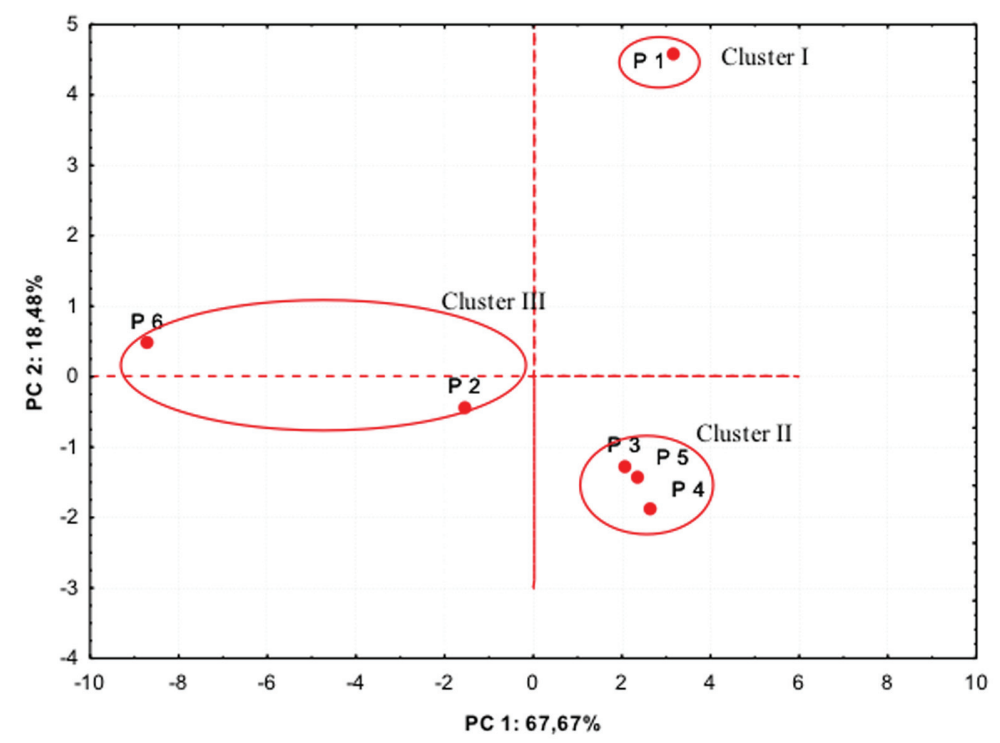

B

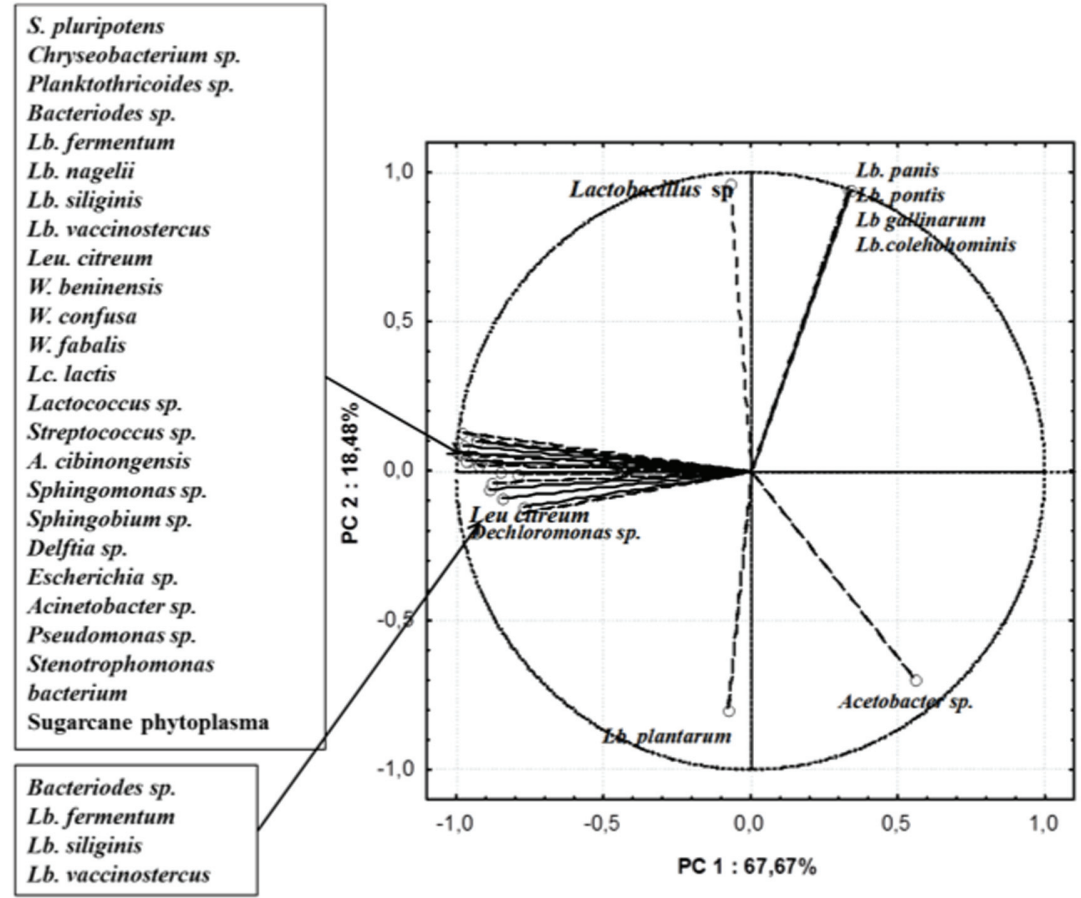

FIGURE 4 | Principal component analysis (PCA) on the relative abundance of bacterial species. (A) Scores (B) Loadings.

were detected, they were represented by DNA bands of lower intensities (Abriouel et al., 2006). Recently Assohoun-Djenia et al. (2016) reported the predominance of L. fermentum, L. plantarum, $P$. pentosaceus, $P$. acidilactici, and $W$. cibaria species in Doklu from Côte d'Ivoire.

The selective pressure of tropical environments may favor microbial biodiversity and highlights a useful technological potential (Chaves-López et al., 2009), and the geographical isolation among the fermented maize dough products leads to great divergent microbial communities, agreeing with the fact that each maize fermented dough can be considered as unique. Nevertheless it is evident that L. plantarum and L. fermentum are important species in fermented maize dough. Kunene et al. (2000) suggested that L. plantarum and L. fermentum associate in spontaneous fermentation of cereals-based foods.

The importance of $L$. fermentum in maize fermentation has been confirmed by previous researches in Ghanan, Benin, Mexican fermented maiz doughs (Agati et al., 1998; Ampe et al., 1999; Hayford et al., 1999; Oguntoyinbo et al., 2011; ObinnaEchem et al., 2014) and the high amylolitic activities found 
in different strains suggest that L. fermentum may be a key organism for fermentation of maize, making the large amounts of starch available to the overall community. In addition, the fermentation products (lactate, formate, and ethanol) may also serve as carbon sources for organisms, such as yeasts (BenOmar and Ampe, 2000). Interestingly, Assohoun-Djenia et al. (2016) reported a high prevalence of bacteriocin-producing L. fermentum strains, and their detection in different stages of Doklu production indicates a high potential of these strains to grow and dominate the microbial population in the fermented maize dough.

The amylolytic activity of some strains of L. plantarum, $L$. lactis, Streptococcus spp. and Leuconostoc mesenteroides had been also reported (Sanni et al., 2002; Díaz-Ruiz et al., 2003). In particular the presence of amylolytic L. plantarum in cereal fermented products is associated to (i) increasing the availability of energy sources for other associated non-amylolytic LAB (ii) contributing to a rapid $\mathrm{pH}$ decrease, and (iii) imparting favorable rheological properties to the dough (Sanni et al., 2002). L. plantarum is considered a highly acid-tolerant LAB that dominates in fermentation processes with vegetables and cereals, due to its metabolic flexibility and low $\mathrm{pH}$ adaptation (Vrancken et al., 2011). Also several strains of this species have been reported to display a broad spectrum of anti-fungal activity (Schnürer and Magnusson, 2005). Thus, it is possible that these features (amylolytic activity, acid tolerance, and bacteriocin production) contributed to the consolidated presence of both L. plantarum and L. fermentum in maize fermented dough.

Acetobacter, which was the second most represented genus in Masa Agria, varied in abundance among the samples, and was particularly abundant in those from producers 3, 4, and 5. Members of this genera are obligately aerobic bacteria that oxidize ethanol to acetic acid, although some species are also able to further oxidize acetic acid completely to $\mathrm{CO}_{2}$ and water (Hutkins, 2006). Different species of the genus Acetobacter have been associated with whole crop maize silage (Oude Elferinck et al., 2001), where they dominate the first step of fermentation (Sträuber et al., 2012), together with LAB. While the presence of acetic acid bacteria in naturally fermented wheat dough, such as sourdough, is uncommon, on the contrary Gluconobacter oxydans and A. xylinum, together with L. saccharolyticum and Saccharomyces cerevisiae have been demonstrated to be important in the fermentation of sorghum grains to produce Hussuwa (El Nour et al., 1999). Acetobacter genus has been also associated with maize doughs (Ampe et al., 1999).

Dough fermentation leads to selective environmental conditions, due to sugar consumption and to the progressive $\mathrm{pH}$ reduction. Being acid-tolerant, and utilizing also molecules other than sugars for their energetic needs, Acetobacter spp. could be selected in the later stage of fermentation. In a polyphasic study on spatial distribution of microorganisms in Pozol from Mexico, Ampe et al. (1999) reported the presence of yeasts, fungi, EPS producers (including members of the genus Leuconostoc), and enterobacteria, as well as other non LAB, such as members of the genus Acetobacter, at the periphery of a pozol ball, in the outer part. Thus it can be hypothesized that samples of producers 3,4, and 5 were collected overall from the surface of the dough, where oxygen should not have been a limiting factor for the growth of this genus, while the low presence found in samples from producers 1, 2, and 6 could probably be related to the poor presence of Acetobacter inside the dough. Further studies on spatial distribution of microorganisms in Masa Agria should be performed to confirm this hypothesis.

The presence of Proteobacteria observed in Masa Agria samples, such as Comamonas, Sphingomonas, Acinetobacter, and Pseudomonas spp., has been also recognized in the first step of rye and durum wheat sourdough fermentation (Ercolini et al., 2013), as flour and environment contaminants. In sourdough these genera usually become dominated by LAB such as Lactobacillus and Weissella in the following fermentation steps. However, it has to be underlined that Masa Agria production does not imply refreshments as in the case of sourdough, but the fermentation first of maize kernels and then of maize dough, therefore determining different dynamics of microbial succession.

Girma et al. (1989) observed that Pseudomonas aeruginosa inoculated in the Ethiopian fermented bread Tef injera, grew well until dough $\mathrm{pH}$ was reduced to 5.5, and thereafter the population decreased until only few viable cells were isolated at $\mathrm{pH}$ 4.0. Nevertheless, Pseudomonas species are characterized by a wide metabolic adaptability to substrates and stressing conditions, thus peculiar species could be selected by the Masa Agria environment. On the other hand, Enterobacteriaceae such as Escherichia, Serratia spp., and Enterobacter aerogenes which could derive from the maize kernels, but more probably from the water used for the dough, were only recognized in samples from producers 2 and 6. It is noteworthy the absence of enteropathogenic species.

Several species of environmental origin were recognized in the different samples and particularly notable are Sphingobium spp. and Dechloromonas spp., playing a role in soil and water bioremediation (Young et al., 2007), and Gemmata spp. (sample 5), a freshwater bacteria originally isolated from Queensland. The presence of Sphingobium spp. is correlated with the water used to wet the maize during Masa Agria production, as it has the capacity to survive in chlorinated waters, allegedly due to the oligotrophic character and the production of biofilms (Vaz-Moreira et al., 2011). This species has been involved in the degradation of chloroacetamide herbicide butachlor (Kim et al., 2013). On the other hand, the relative abundance of Phytoplasma, a plant pathogen able to cause maize bushy stunt that is among the most widespread diseases in herbaceous hosts, causing severe yield losses, may be assumed by the fact that the dough samples from producers 1,2 , and 6 were presumptively obtained from maize of low quality.

The complex microbiota of Masa Agria included also some less-abundant species such as some Lactobacillus (curvatus, rossiae, and silingis), and $L$. citrineum that migh play an important role in effectiveness and stability of the microbial community, as their microbial metabolism provides molecules able to affect this food ecosystem. 
The combined application of culture-dependent and cultureindependent analytical strategies allowed us to obtain an insight on the richness of the microbiota of Masa Agria, providing information on the diversity and on the relative abundance of microbial species.

\section{CONCLUSION}

For the first time, this study explored the microbial diversity of Masa Agria, by pyrosequencing of 16S rRNA gene amplicons. Our results elucidated the structures of the bacterial communities of six samples obtained from different producers, identified specific dominant species, and suggested the presence of possibly unknown microorganisms.

In particular, this research was focused on bacterial characterisation at the end of fermentation in commercial samples. Further investigations are needed to evaluate the

\section{REFERENCES}

Abriouel, H., Ben-Omar, N., López, R. L., Martínez-Cañamero, M., Keleke, S., and Gálvez, A. (2006). Culture-independent analysis of the microbial composition of the African traditional fermented foods poto poto and dégué by using three different DNA extraction methods. Int. J. Food Microbiol. 111, 228-233. doi: 10.1016/j.ijfoodmicro.2006.06.006

Agati, V., Guyot, J.-P., Morlon-Guyot, J., Talamond, P., and Hounhouigan, J. (1998). Isolation and characterization of new amylolytic strains of Lactobacillus fermentum from fermented maize doughs (mawe and ogi) from Benin. J. Appl. Microbiol. 85, 512-520. doi: 10.1046/j.1365-2672.1998.853527.x

Ampe, F., Ben-Omar, N., Moizan, C., Wacher, C., and Guyot, J.-P. (1999). Polyphasic study of the spatial distribution of microorganisms in Mexican pozol, a fermented maize dough, demonstrates the need for cultivationindependent methods to investigate traditional fermentations. Appl. Environ. Microbiol. 65, 5464-5473.

Annan, N. T., Poll, L., Sefa-Dedeh, S., Plahar, W. A., and Jakobsen, M. (2003). Volatile compounds produced by Lactobacillus fermentum, Saccharomyces cerevisiae and Candida krusei in single starter culture fermentations of Ghanaian maize dough. J. Appl. Microbiol. 94, 462-474. doi: 10.1046/j.13652672.2003.01852.x

Assohoun-Djenia, N. M. C., Djenia, N. T., Messaoudic, S., Lhommeb, E., Koussemon-Camaraa, M., Ouassad, T., et al. (2016). Biodiversity, dynamics and antimicrobial activity of lactic acid bacteria involved in the fermentation of maize flour for doklu production in Côte d'Ivoire. Food Control 62, 397-404. doi: 10.1016/j.foodcont.2015.09.037

Ben-Omar, N., and Ampe, F. (2000). Microbial community dynamics during production of the Mexican fermented maize dough Pozol. Appl. Environ. Microbiol. 66, 3664-3673. doi: 10.1128/AEM.66.9.3664-3673.2000

Chao, Y., Liping, M., Yang, Y., Ju, F., Zhang, X.-X., Wu, W.-M., et al. (2013). Metagenomic analysis reveals significant changes of microbial compositions and protective functions during drinking water treatment. Sci. Rep. 3:3550. doi: 10.1038/srep03550

Chaves-López, C., Serio, A., Grande-Tovar, C. D., Cuervo-Mulet, R., DelgadoOspina, J., and Paparella, A. (2014a). Traditional fermented foods and beverages from a microbiological and nutritional perspective: the Colombian heritage. Compr. Rev. Food Sci. Food Saf. 13, 1031-1048. doi: 10.1111/1541-4337.12098

Chaves-López, C., Serio, A., Osorio-Cadavid, E., Paparella, A., and Suzzi, G. (2009). Volatile compounds produced in wine by Colombian wild Saccharomyces cerevisiae strains. Ann. Microbiol. 59, 733-740. doi: 10.1007/BF03179216

Chaves-López, C., Serio, A., Paparella, A., Martuscelli, M., Corsetti, A., Tofalo, R., et al. (2014b). Impact of microbial cultures on proteolysis and release of bioactive peptides in fermented milk. Food Microbiol. 42, 117-121. doi: 10.1016/j.fm.2014.03.005 microbial dynamics throughout the manufacturing process and to investigate the role of the different bacterial groups during fermentation.

\section{AUTHOR CONTRIBUTIONS}

CL: Devised and drafted the manuscript-statistical analyses. AS: drafted the manuscript. JO: molecular analysis. CR: culture dependent analyses. CT: statistical analyses. AP: manuscript revision.

\section{SUPPLEMENTARY MATERIAL}

The Supplementary Material for this article can be found online at: http://journal.frontiersin.org/article/10.3389/fmicb. 2016.01168

Cole, J. R., Wang, Q., Cardenas, E., Fish, J., Chai, B., Farris, R. J., et al. (2009). The ribosomal database project: improved alignments and new tools for rRNA analysis. Nucleic Acids Res. 37, D141-D145. doi: 10.1093/nar/gkn879

De Vuyst, L., Van Kerrebroeck, S., Harth, H., Huys, G., Daniel, H.-M., and Weckx, S. (2014). Microbial ecology of sourdough fermentations: diverse or uniform? Food Microbiol. 37, 11-29. doi: 10.1016/j.fm.2013.06.002

Díaz-Ruiz, G., Guyot, J. P., Ruiz-Teran, F., Morlon-Guyot, J., and Wacher, C. (2003). Microbial and physiological characterization of weakly amylolytic but fast-growing lactic acid bacteria: a functional role in supporting microbial diversity in Pozol, a Mexican fermented beverage. Appl. Environ. Microbiol. 69, 4367-4374. doi: 10.1128/AEM.69.8.4367-4374.2003

Dowd, S. E., Zaragoza, J., Rodriguez, J. R., Oliver, M. J., and Payton, P. R. (2005). Windows. NET network distributed basic local alignment search toolkit (W.ND-BLAST). BMC Bioinformatics 6:93. doi: 10.1186/1471-2105-6-93

El Nour, M. E. M., El-Tigani, S., and Dirar, H. A. (1999). A microbiological study of Hussuwa: a traditional Sudanese fermented food from germinated Sorghum bicolor c.v. feterita. World J. Microbiol. Biotechnol. 15, 305-308. doi: 10.1023/A:1008849218617

Elizaquível, P., Pérez-Cataluña, A., Yépez, A., Aristimuño, C., Jiménez, E., Cocconcelli, P. S., et al. (2015). Pyrosequencing vs. culture-dependent approaches to analyze lactic acid bacteria associated to chica, a traditional maize-based fermented beverage from Northwestern Argentina. Int. J. Food Microbiol. 198, 9-18. doi: 10.1016/j.ijfoodmicro.2014.12.027

Ercolini, D., Pontonio, E., De Filippis, F., Minervini, F., La Storia, A., Gobbetti, M., et al. (2013). Microbial ecology dynamics during rye and wheat sourdough preparation. Appl. Environ. Microbiol. 79, 7827-7836. doi: 10.1128/AEM.02955-13

Escalante, A., Wacher, C., and Farrés, A. (2001). Lactic acid bacterial diversity in the traditional Mexican fermented dough pozol as determined by $16 \mathrm{~S}$ rDNA sequence analysis. Int. J. Food Microbiol. 64, 21-31. doi: 10.1016/S01681605(00)00428-1

Giraffa, G. (2002). Enterococci from foods. FEMS Microbiol. Rev. 26, 163-171. doi: 10.1111/j.1574-6976.2002.tb00608.x

Girma, M., Gashe, B. A., and Lakew, B. (1989). The effetc of fermentation on the growth and survival of Salmonella typhimurium, Staphylococcus aureus, Bacillus cereus and Pseduomonas aeruginosa in fermenting tef (Eragrostis tef). World J. Microbiol. Biotechnol. 5, 61-66. doi: 10.1007/BF01724960

Gontcharova, V., Youn, E., Wolcott, R. D., Hollister, E. B., Gentry, T. J., and Dowd, S. E. (2010). Black box chimera check (B2C2): a windows-based software for batch depletion of chimeras from bacterial 16S rRNA gene datasets. Open Microbiol. J. 4, 47-52. doi: 10.2174/1874285801004010047

Gowen, C. M., and Fong, S. S. (2010). Genome-scale metabolic model integrated with RNAseq data to identify metabolic states of Clostridium thermocellum. Biotechnol. J. 5, 759-767. doi: 10.1002/biot.201000084 
Halm, M., Lillie, A., Sørensen, A. K., and Jakobsen, M. (1993). Microbiological and aromatic characteristics of fermented maize doughs for kenkey production in Ghana. Int. J. Food Microbiol. 19, 135-143. doi: 10.1016/0168-1605(93) 90179-K

Hastorf, C. A., and Johannessen, S. (1993). Pre-Hispanic political change and the role of maize in the Central Andes of Peru. Am. Anthropol. 95, 115-138. doi: 10.1525/aa.1993.95.1.02a00060

Hayford, A. E., Petersen, A., Vogensen, F. K., and Jakobsen, M. (1999). Use of conserved randomly amplified polymorphic DNA (RAPD) fragments and RAPD pattern for characterization of Lactobacillus fermentum in Ghanaian fermented maize dough. Appl. Environ. Microbiol. 65, 3213-3221.

Heberle, H., Meirelles, G. V., da Silva, F. R., Telles, G. P., and Minghim, R. (2015). InteractiVenn: a web-based tool for the analysis of sets through Venn diagrams. BMC Bioinformatics 16:169. doi: 10.1186/s12859-015-0611-3

Kim, N. H., Kim, D. U., and Ka, J. O. (2013). Syntrophic biodegradation of butachlor by Mycobacterium sp. J7A and Sphingobium sp. J7B isolated from rice paddy soil. FEMS Microbiol. Lett. 344, 114-120. doi: 10.1111/1574-6968.12163

Kircher, S. M., Dick, N., and Sturm, K. (2002). "Comparison of BBL ${ }^{\mathrm{TM}}$ CHROMafar $^{\mathrm{TM}}$ Staph aureus to other commonly used media for the presumptive identification of Staphylococcus aureus," in Poster at the 101st General Meeting of the American Society for Microbiology (ASM): Poster C-20, Salt Lake City, UT.

Klein, G., and Reuter, G., (2012). "Culture media for enterococci," in Handbook of Culture Media for Food and Water Microbiology, 3rd Edn, eds J. E. L. Corry, G. D. W. Curtis, and R. M. Baird (Cambridge: RCS Publishing), 165.

Krueger, C. L., and Sheikh, W. (1987). A new selective medium for isolating Pseudomonas spp. from water. Appl. Environ. Microbiol. 53, 895-897.

Kunene, N. F., Geornaras, I., von Holy, A., and Hastings, J. W. (2000). Characterization and determination of origin of lactic acid bacteria from a sorghum-based fermented food by analysis of soluble proteins and amplified fragment length polymorphism fingerprinting. Appl. Environ. Microbiol. 66, 1084-1092. doi: 10.1128/AEM.66.3.1084-1092.2000

Hutkins, R. W. (ed.) (2006). Microbiology and Technology of Fermented Foods. Oxford: Blackwell Publishing Ltd. doi: 10.1002/9780470277515

Minervini, F., Lattanzi, A., De Angelis, M., Celano, G., and Gobbetti, M. (2015). House microbiotas as sources of lactic acid bacteria and yeasts in traditional Italian sourdoughs. Food Microbiol. 52, 66-76. doi: 10.1016/j.fm.2015.06.009

Obinna-Echem, P. C., Kuri, V., and Beal, J. (2014). Evaluation of the microbial community, acidity and proximate composition of akamu, a fermented maize food. J. Sci. Food Agric. 94, 331-340. doi: 10.1002/jsfa.6264

Oguntoyinbo, F. A., Tourlomousis, P., Gasson, M. J., and Narbada, A. (2011). Analysis of bacterial communities of traditional fermented West African cereal foods using culture independent methods. Int. J. Food Microbiol. 145, 205-210. doi: 10.1016/j.ijfoodmicro.2010.12.025

Oude Elferinck, S. J., Driehuis, F., Becker, P. M., Gottschal, J. C., Faber, F., and Spoelstra, S. F. (2001). The presence of Acetobacter sp. in ensiled forage crops and ensiled industrial byproducts. Meded. Rijksuniv. Gent Fak. Landbouwkd. Toegep. Biol. Wet. 66, 427-430.

Sakamoto, N., Tanaka, S., Sonomoto, K., and Nakayama, J. (2011). 16S rRNA pyrosequencing-based investigation of the bacterial community in nukadoko, a pickling bed of fermented rice bran. Int. J. Food Microbiol. 144, 352-359. doi: 10.1016/j.ijfoodmicro.2010.10.017

Sanni, A. I., Morlon-Guyot, J., and Guyot, J. P. (2002). New efficient amylaseproducing strain of Lactobacillus plantarum and L. fermentum isolated from different Nigerian traditional fermented foods. Int. J. Food Microbiol. 72, 53-62. doi: 10.1016/S0168-1605(01)00607-9

Schnürer, J., and Magnusson, J. (2005). Antifungal lactic acid bacteria as biopreservatives. Trends Food Sci. Technol. 16, 70-78. doi: 10.1016/j.tifs.2004.02.014

Serio, A., Chaves-López, C., Paparella, A., and Suzzi, G. (2010). Evaluation of metabolic activities of enterococci isolated from Pecorino Abruzzese cheese. Int. Dairy J. 20, 459-464. doi: 10.1016/j.idairyj.2010.02.005

Sträuber, H., Schröder, M., and Kleinsteuber, S. (2012). Metabolic and microbial community dynamics during the hydrolytic and acidogenic fermentation in a leach-bed process. Energy Sustain. Soc. 2:13. doi: 10.1186/2192-0567-2-13

Suchodolski, J. S., Dowd, S. E., Wilke, V., Steiner, J. M., and Jergens, A. E. (2012). 16S rRNA gene pyrosequencing reveals bacterial dysbiosis in the duodenum of dogs with idiopathic inflammatory bowel disease. PLoS ONE 7:39333. doi: 10.1371/journal.pone.0039333

Vaz-Moreira, I., Nunes, O. C., and manaia, C. M. (2011). Diversity and antibiotic resistance patterns of Sphingomonadaceae isolates from drinking water. Appl. Environ. Microbiol. 77, 5697-5706. doi: 10.1128/AEM.00579-11

Vrancken, G., De Vuyst, L., Rimaux, T., Allemeersch, J., and Weckx, S. (2011). Adaptation of Lactobacillus plantarum IMDO 130201, a wheat sourdoughisolate, to growth in wheat sourdough simulation medium at different $\mathrm{pH}$ values through differential gene expression. Appl. Environ. Microbiol. 77, 3406-3412. doi: 10.1128/AEM.02668-10

Young, C. C., Ho, M.-J., Arun, A. B., Chen, W.-M., Lai, W.-A., Shen, F.-T., et al. (2007). Sphingobium olei sp. nov., isolated from oil-contaminated soil. Int. J. Syst. Evol. Microbiol. 57, 2613-2617. doi: 10.1099/ijs.0.65187-0

Conflict of Interest Statement: The authors declare that the research was conducted in the absence of any commercial or financial relationships that could be construed as a potential conflict of interest.

Copyright (c) 2016 Chaves-Lopez, Serio, Delgado-Ospina, Rossi, Grande-Tovar and Paparella. This is an open-access article distributed under the terms of the Creative Commons Attribution License (CC BY). The use, distribution or reproduction in other forums is permitted, provided the original author(s) or licensor are credited and that the original publication in this journal is cited, in accordance with accepted academic practice. No use, distribution or reproduction is permitted which does not comply with these terms. 